Loudon, L. \& Hall. H. (2010). From triviality to business tool: the case of Twitter in library and information services delivery. Business Information Review, 27(3).

\title{
From triviality to business tool: the case of Twitter in library and information services delivery
}

\section{By Lynn Loudon and Hazel Hall, Edinburgh Napier University}

Corresponding author: Hazel Hall, h.hall@napier.ac.uk, @hazelh

This is the version of the article that was submitted to Business Information Review. The final, definitive version of this paper will be published in Business Information Review, 27(3) by SAGE publications Ltd. All rights reserved (C) Lynn Loudon and Hazel Hall

\section{Abstract}

This article evaluates microblogging in general, and Twitter in particular, as a professional tool in library and information services provision. It draws on the findings of a study completed in 2010 based on survey and interview responses of over 300 librarian participants.

Keywords: information services, libraries, microblogging, social software, Twitter

\section{Introduction}

Much of the mainstream press on microblogging in general, and Twitter in particular, focuses on the application of such tools for general purposes of communication, for example, for marketing and public relations, or social networking between contacts. Considered here are their potential in a specific professional environment: library and information services. The discussion is based on research conducted in 2010 that investigated the deployment of Twitter amongst librarians, primarily for information services provision, and as a platform to support professional development and collaborative working. The difficulties of integrating a new technology into services delivery where its full potential is not understood - and in some cases doubted - are also covered.

\section{Libraries, librarians and social software}

Librarians are committed to adding to the value of information services delivery. They are keen to develop applications that will bring them to the attention of new generations of users. A recent focus has been social software tools - in particular those labelled as "social networking" and 
Loudon, L. \& Hall. H. (2010). From triviality to business tool: the case of Twitter in library and information services delivery. Business Information Review, 27(3).

"microblogging" - and their applicability to information services work (Shoniwa and Hall, 2008, p. 5). Research shows that such tools can be deployed to improve communication, both with users of library and information services, and internal colleagues. They can also be put to good effect to facilitate knowledge sharing among staff (Farkas, 2007, p. 8). Studies point to the requirement for librarians to be adept in the use of social software so that they can capitalise both on the communication opportunities they present, and to access quality information from the vast amount of content that they make available (Murphy and Moulaison, 2009, p. 2).

Of the range of social software, microblogging is one of the most interesting, yet least understood: it is often said that it takes time for people to "get" microblogging. See, for example the step diagram that illustrates the "Five stages of Twitter acceptance": denial, presence, dumping, conversing and microblogging (Lee, 2008). Hall (2009) has argued that the lack of understanding is partly due to the apparent simplicity, and - in some cases - frequently mistaken triviality, of a tool that offers enormous flexibility for sophisticated use. A microblogging application combines key features of blogging, the practicality of instant messaging and the mobility of SMS texting (as noted by, for example, Brown, 2008). Added to this, it offers the potential for new knowledge creation similar to the functionality that wikis furnish in the aggregation of conversations across communities. Microblogging tools also display particular strengths as social networking applications, not least because they allow for both symetrical and asymetrical relationships. This is in contrast to "pure" social networking applications, such as Facebook, where until recently only reciprocal friendships could be forged. The advantage of the microblogging follower (as opposed to friendship) model is that less-expert lurkers may engage in legitimate peripheral participation as they learn from the more experienced members of the online communities to which they may later contribute more fully. A further characteristic of microblogging, and one that strengthens its appeal at the most basic level of human communications behaviour, is how it replicates elements of conversation. Ideas and questions are shared in brief communications (metaknowledge), responses follow - in some cases to confirm the nature of a suggestion or request further information (problem reformulation) - further contributions to the discussion may ensue until the discussion ends (validation), and from it opinions are formed (legitimization) (Hall, 2009).

Twitter is the best-known publicly accessible microblogging application. Launched in 2006, it caters for an environment in which people use a wide variety of platforms, including mobile devices, to communicate and share information at speed, when it suits them (Good, 2007, p. 1). It has spawned a great number of third party applications which allow the filtering of information from specific sources, and the discovery of resources relating to particular subjects. Such 
Loudon, L. \& Hall. H. (2010). From triviality to business tool: the case of Twitter in library and information services delivery. Business Information Review, 27(3).

software enhances the value of Twitter as a dynamic service and has increased its popularity among users (Brown, 2008).

It is recognized, however, that the long-term value of Twitter has been debated. For example, in 2008 it was intimated that this application might simply be the latest in a succession of sensations that appear suddenly then die away almost as quickly, or a symptom of a society too heavily reliant on digital communication through social networking (Brown, 2008). Around the same time such suggestions were countered by others. For example, it was emphatically declared that there was no "turning back from this phenomenon" which had "created expectations for mediated social maintenance" in the long-term (Libraries and social networking, 2007). Recent reports of Twitter's phenomenal growth - for example, registered users at 150 million and traffic of 70 million tweets a day as of September 2010 (Twitter by the numbers, 2010) - as well as the term "Twitter" entering everyday parlance, serve as evidence of current Twitter "embeddedness".

For those who work in library and information services, a significant danger associated with microblogging in general, and with Twitter in particular, is ignorance of its full functionality. The commonly mistaken view is that Twitter simply offers a cut-down version of the Facebook status update box, with the added bonus that anyone can become a "friend" of a celebrity. Research completed by Napier University and TFPL in 2008 highlighted that the failure of information professionals to recognise and embrace social software was a real business risk (Hall, Golzari, Blaswick \& Goody, 2008). Indeed, the study revealed that this particular risk was regarded by information and knowledge managers as one that surpasses the more frequently cited possible dangers of the adoption of social software in the workplace. Risks related to information management (for example, information sprawl, information overload, archiving and version control), information security (for example, legal infringement, leakage of confidential information), lowered productivity, and antisocial behaviour were all deemed less prominent than the danger of missing the potential business opportunities offered by social software applications.

Previously published research shows that libraries and librarians have attempted to take advantage of social software to cultivate relationships and increase user engagement. At a local level, social software can be deployed to help promote services and - with a raised awareness of the services on offer - such services are then rendered more accessible to a widened user-base. Thus a positive outcome of efforts to develop a strategy for the deployment of social software in libraries has been extension of reach to sections of the community that did not previously take advantage of such services (Fernandez, 2009, p. 3). This is perhaps the most obvious application of Twitter in information services provision: as a form of combined marketing and current awareness service where librarians push messages out to the user-base. It has also been noted 
Loudon, L. \& Hall. H. (2010). From triviality to business tool: the case of Twitter in library and information services delivery. Business Information Review, 27(3).

that Twitter has further applications for the professional development of librarians, largely because it allows individuals to network with professional peers, regardless of time and geographic constraints (Brown, 2008). This facility, in turn, contributes to improved services delivery in that librarians who take their professional development seriously - in this case by learning from the practice of others by strategic "follow" relationships - will have more ideas to contribute for enhanced services provision.

The 2010 study discussed in this article sought to investigate further these two purposes of Twitter use amongst the professional library community, viz for (1) combined marketing and current awareness and (2) professional development. It also acknowledged that publications disseminated soon after Twitter's launch tend to reflect practice and experience of early adopters. It was suspected that such work no longer reflects Twitter's current functionality, especially now that it is becoming further embedded in everyday library practice. Thus the study reported below explores Twitter use by librarians in 2010 across a range of functions.

The findings of the work are based on the analysis of data from two sources: (1) 299 returns from a web-based survey, and (2) in-depth interviews with eleven individuals. It should be noted that the initial focus of this project was Twitter adoption for UK academic library and information services provision. Considerable effort was therefore made to ensure that all UK academic library and information services were aware of the study: the member organizations of the Society of College, National and University Libraries (SCONUL) were all invited by e-mail to participate in the study. The call for participation was then further disseminated by e-mail across all UK library sectors. Tweeting and retweeting of the survey link also encouraged participation from librarians of different backgrounds from both within and beyond the UK.

\section{Twitter for information services delivery: 2010 findings}

It is clear from the results of the survey that librarians believe that library and information services should embrace new technologies, and actively engage with them as information delivery tools, taking into account end-user preferences. As to the question of the value of Twitter for information delivery, just under three quarters of the surveyed population believed that Twitter was a valuable extension to the range of tools available. 34\% were already using Twitter for this purpose, with another $15 \%$ reporting occasional use.

The most frequent deployment of Twitter cited by the survey respondents was for news and current awareness. For example, tweets relay news of library events, new library resources and services, and changes to opening hours. They also provide links to other online resources. Some 
Loudon, L. \& Hall. H. (2010). From triviality to business tool: the case of Twitter in library and information services delivery. Business Information Review, 27(3).

respondents cited other types of information that can be disseminated by Twitter, such as details of the availability of popular books. Interviewee data provided detailed illustrations of the ways that Twitter serves as a broadcast news service. For example, mention was made of the announcement of early services closures during the adverse UK winter weather in 2009/10, and news of the outbreak of Swine Flu in 2009. As well as direct reference to types of news and current awareness disseminated by Twitter, study participants also demonstrated how Twitter supports "back office" functions that contribute to information services delivery, for example in providing an additional resource for enquiry work.

These examples of how Twitter contributes to news and current awareness demonstrate its function at two levels. First, it replicates traditional services delivery. For example, announcements related to changes in library opening hours will also be communicated across other media such as posters and web pages, and - in the case of closed user groups - by e-mail and updates to intranet sites etc. A further observation is that it is evident that in this context Twitter can enhance traditional practice. Services that are too labour-intensive otherwise, such as making public the availability of individual texts as they are issued and discharged, may be offered. It is also worth noting here how library Twitter accounts take on an institutional role in cases where they make announcements on behalf of an organisation such as a university ${ }^{1}$, thus extending the bounds of their traditional core responsibilities.

The study uncovered several reasons why Twitter is seen as an appropriate mechanism for the delivery of new and current awareness announcements of the nature highlighted above. The survey respondents most commonly made reference to the ease of use and immediacy of the tool. As one noted: "It's quick, current and easy dissemination of information to [our] users and other interested parties". Interviewees highlighted the character limitation of tweets a great bonus because it forces communication that is to the point. Study participants also noted the ease with which Twitter can be accessed over a range of platforms, both within the library environment and remotely. This allows libraries and librarians to maintain contact with registered end-users (especially if they follow back), as well as connect to new communities: "It is enabling us to reach a new section of our customers and for them to reach us". A further advantage of engaging with end-users over Twitter derives from the survey and interview data. To be seen as an active user of new tools can raise the profile of library and information services.

\footnotetext{
${ }^{1}$ This reflects common practice for the introduction of novel technologies within large institutions. For example, in the 1980s the first institutional fax machines were commonly located within libraries.
} 
Loudon, L. \& Hall. H. (2010). From triviality to business tool: the case of Twitter in library and

information services delivery. Business Information Review, 27(3).

These findings show how librarians use Twitter to extend traditional information services delivery. However, it is worth noting the emphasis on using the application as a broadcasting tool to push information out to the user-base. It could be argued here that the full potential of Twitter, particularly in terms of new services delivery derived from increased user engagement, is yet to be realised within the library environment.

\section{Twitter for professional development and personal use: 2010 findings}

The results of this study also demonstrate how librarians use Twitter in the workplace for purposes other than direct support of information services provision. $74 \%$ of the survey respondents felt that Twitter is a useful resource for professional development. This is achieved primarily by following feeds from professional organizations (for example, @LISResearch) and high profile library and information professionals active on Twitter (for example, @PhilBradley). Within the population surveyed it was believed that general communication and online networking between librarians, and the relay and receipt of more specific communications such as the advertising of forthcoming professional events, support professional development.

A survey response gives an example of an individual strategy for using Twitter as a professional development tool: "I use it as a type of referencing service in that I retweet articles of interest to me which I can go back to later and find should I require them if I am conducting a particular research project." Another explained how observing the tweets of other library and information services helped establish the best means of deploying the tool locally within the home institution. At the level of the community, hash-tagged tweeting at conferences for the benefit of others attending (both in person and remotely) illustrates how the tool can be harnessed for the professional development of a group of individuals. As a further example of how Twitter serves as a professional development tool, findings from this research show how new follow relationships can develop into stronger associations between individuals, and within communities, over time, and in some cases may lead to collaborative work.

More personal uses of Twitter uncovered by this study reveal that although it has a role to play in "public" personal activities, it is more rarely used as a platform for more intimate social interaction. So, for example, librarians will turn to Twitter to help make decisions over a domestic purchase, catch up on the latest news about their favourite celebrities, or engage in a major media event in a similar way to tweeting and following hash-tagged conference content. However, for social interaction with friends or family, librarians are far more likely to turn to Facebook. This, of course, makes sense when the different linking models for each of these applications ("friend" and "follower" as noted above) are taken into consideration. 
It is also worth noting here that study participants referred to the ease with which Twitter output may be analysed to investigate individuals. This demonstrates an awareness of how Twitter activity exhibits information on which professional reputations may be built, as well as hints as to a further reason why librarians are less likely to broadcast personal information across this platform.

\section{Barriers to widespread Twitter adoption within the library community: 2010 findings}

While it is clear that there is enthusiasm for Twitter amongst the participants in this study (and it should also be acknowledged that many were recruited through Twitter), it is worth considering the drawbacks of its inclusion in the librarian's repertoire. Just over a third of survey respondents (106) highlighted difficulties in integrating Twitter into their work. Their main complaints related to the time to be devoted to keeping up with information generated by Twitter contacts, the quantity of irrelevant material to be consumed in the course of identifying news and information of genuine value, and the distraction from other tasks that Twitter can represent. There are indications from the study that these issues were more frequently raised by less-experienced Twitter users. It is likely that at the time that data were collected for this research these users had not yet established their core Twitter contact community of key informants and were not familiar with the use of lists. Nor were they yet familiar with Twitter clients that offer more sophisticated interfaces for managing Twitter accounts than that available at the time of the empirical study at http://www.twitter.com. (In contrast, it was clear that more experienced survey respondents coped more easily with incoming information flows, and used advanced functions such as those which offer the facility to schedule outgoing tweets while account holders are busy with other tasks.) Users in the early stages of Twitter adoption often exhibit frustration with the limitations of the 140 character limitation of a tweet, whereas the more experienced treat their tweets as part of an integrated communication strategy that encompasses other social software applications, most notably a blog to which their tweets point. Although not explored in this study, the question of individual versus institutional identity appears to be an issue with librarians new to Twitter. Where a librarian sets up a single account for all work purposes there is confusion over audience. New users are better advised to consider setting up at least two accounts: one for interactions with library users (for example, for news and current awareness) and one for interactions with professional contacts (for example, for professional development).

Convincing others of the value of Twitter for library and information services provision also emerged as a barrier to widespread adoption. Findings from this research indicate that the respondents are generally acting on their own initiative when it comes to devising and 
Loudon, L. \& Hall. H. (2010). From triviality to business tool: the case of Twitter in library and information services delivery. Business Information Review, 27(3).

implementation a strategy for the deployment of Twitter in the workplace. There seems to be little guidance or support from management in such activity. For example, several interviewees stated that their library management teams still needed convincing of the benefits of using Twitter. Similarly, interviewees and survey respondents noted that persuading reluctant fellow staff members that Twitter has valuable practical uses has been particularly problematic. Some highlighted how Twitter has been stigmatised as trivial, deployed solely for keeping up to date with the mundane activities of celebrities without any acknowledgement of its varied purposes. As one complained: "Some people think it's a trend, and don't pay it any attention. The celebrity interaction can have a negative effect, as some people think that is all it is about and refuse to see the use of it." This can be galling to keen tweeters, such as the survey respondent in this study who enthusiastically declared that Twitter was "one of the most useful tools I've utilised!"

For those working in higher education, and an issue noted in particular by interviewees, was that although there is some enthusiasm for Twitter amongst research and teaching staff, there is little within the student body: Twitter is not as popular among young people as other social networking applications such as Facebook. In addition, there was the impression amongst study participants that some students actually feel that social networking applications do not have a formal use. This reflects opinion amongst some library management teams and immediate colleagues as noted above.

A further barrier to widespread Twitter adoption is that some libraries have restrictions in place that govern the use of social software applications by staff, and these can prohibit full engagement with some valuable tools.

Many of these barriers recall problems encountered with the introduction of other earlier technologies. The challenges of finding the "right" Twitter community, "getting" Twitter and becoming skilled in crafting 140-word messages all match with issues tackled by e-mail users in the late 1980s and early 1990s: establishing e-mail list registrations; understanding how e-mail "works" in terms of integrating it into daily practice, establishing and learning the etiquette of email use etc. Librarians pioneering the development of a service with limited support from management and immediate colleagues aligns well with early work on web page and intranet design efforts. The blanket banning of social software without careful consideration has parallels with organisational restrictions on web page access in the mid-1990s.

In some respects then, it should not be surprising that there is resistance to the adoption of a new tool amongst those who do not understand its potential. This should not, however, distract librarians who know the benefit of Twitter in the workplace from the job of persuading their 
Loudon, L. \& Hall. H. (2010). From triviality to business tool: the case of Twitter in library and information services delivery. Business Information Review, 27(3).

employers to adopt an institutional approach to the use of Twitter and associated tools. The risk of not doing so is missed opportunity for improved services provision, as noted in the NapierTFPL study in 2008 (Hall et al, 2008).

\section{Conclusion}

While there are challenges to the deployment of Twitter as a formal tool for information services delivery, this study reveals that there exists a keen community of librarians who have embraced Twitter for work purposes. Their main uses of Twitter are for disseminating news and current awareness at both a service and institutional level, and for professional development. Of these two broad applications, the evidence from the empirical study reveals that the mode of Twitter interaction between libraries and end-users is less sophisticated than that of corresponding librarians. For the former Twitter is used primarily as an additional means of broadcasting information. In contrast to this the interactions between librarians show how fuller advantage is taken of the flexibility of a tool that offers more than a simple one-way communication channel.

In addition, Twitter has been found to be useful in extending the reach of library and information services, as well a presenting an up to date image of services provision. As Twitter use becomes more widespread and its understanding as a formal tool with multiple serious applications, this community is expected to grow and - with an enlarged user-base - build on current practice for improved information services delivery. As is the case with more established communication media, such as the telephone, the question as to whether it is a triviality or not depends how it is adopted and adapted by the user community, and subsequent changes in information behaviour and use.

\section{Acknowledgements}

The authors thank the survey respondents and interviewees for participating in the empirical study. They are also grateful to @darcie, @jonmountjoy, @queens_hall and @salidatious for comments on the manuscript.

\section{References}

Brown, L. (2008, September). Twittering Libraries. Available at http://lis5313.ci.fsu.edu/wiki/index.php/Twittering_Libraries 
Loudon, L. \& Hall. H. (2010). From triviality to business tool: the case of Twitter in library and information services delivery. Business Information Review, 27(3).

Farkas, M. (2007). Social software in libraries: building collaboration, Communication and community online. Medford, N.J.: Information Today

Fernandez, J. (2009). A SWOT analysis for social media in libraries. Online 35(3). Available at http://findarticles.com/p/articles/mi hb3328/is 200909/ai n39230796/?tag=content;col1

Good, R. (2007, July). Twitter: A beginner's Guide, Part 2. Retrieved October 4, 2009 from http://www.webjunction.org/community-firtt/articles/content/449937

Hall, H., Golzari, S., Blaswick, B., \& Goody, M. (2008). Opportunity and risk in social computing environments. Available at

http://www.soc.napier.ac.uk/ hazelh/esis/soc_comp_proj_rep_public.pdf

Hall, H. (2009). When social means business: the potential of social computing tools to support collaborative work as part of the organisational information infrastructure. Invited keynote paper presented at Innovation in e-information, Manchester 16-17 June 2009. Available at http://www.dcs.napier.ac.uk/ hazelh/esis/Hall_UKelG_keynote.ppt

Lee, M. (2008) How Twitter changed my life. Available at http://www.slideshare.net/minxuan/howtwitter-changed-my-life-presentation

Libraries and social networking (2007) The thoughts of nine experts about our increasingly online lives. Available at http://www.oclc.org/nextspace/007/1.htm

Murphy, J. \& Moulaison, H. (2009). Social networking literacy competencies for librarians: exploring considerations and engaging participation. Available at http://www.ala.org/ala/mgrps/divs/acrl/events/national/seattle/papers/328.pdf

Shonwia, P., \& Hall, H. (2008). Library 2.0 and UK academic libraries: drivers and impacts. New Review of Information Networking, 14(2), 69-79.

Twitter by the numbers (2010) Available at http://www.slideshare.net/raffikrikorian/twitter-by-thenumbers 